\title{
Impressions of Physiotherapy in South Africa
}

\author{
Miss A. M. BODOANO, M.P.S.C., Principal Pretoria Hospital School of Physiotherapy
}

\begin{abstract}
S I am a very newcomer to this Country, it would be A unwise of anyone who may read this, to take what I say too seriously. With the. exception of the Pretoria Hospital School of Physiotherapy, the impressions I have received of Physiotherapy in this country, are the result of only very brief glimpses, and coloured by the pleasure I experience in being here and the stimulation of new surroundings and new faces.
\end{abstract}

Until a few weeks of my coming out here to take the post as Principal of the Pretoria Hospital School of Physiotherapy, I knew virtually nothing of the position of Physiotherapy in South Africa. I had a vague idea that there were some training schools and I had seen Miss Margaret Roper just before she came out to Cape Town to start a new school, but had not inquired further into the situation.

In a matter of hours in February last year, my whole attention was focussed on South Africa, and I very quickly learned that there was a flourishing school at the University of Witwatersrand about to celebrate its 21 st birthday, that the school in Cape Town was approaching its first birthday and that there was a large school in Pretoria almost 8 years old, but orphaned due to lack of teaching staff.

Stimulated by this challenge I undertook to do what I could to help the school, and came out here in June last bringing with me Miss Anne Savin to assist me, and four months later coaxed Miss E. M. Meredith to leave a life of leisure and retirement to come and help also.

We were delighted with the set up of the school, its excellent accommodation, lavish electrical apparatus and 64 enthusiastic students avid for knowledge. In considering Physiotherapy training in the school, I think that one of the greatest assets is the close liason between the school and the Pretoria University, and the tremendous amount of help given in the training of our students by the Anatomy and Physiology Departments of the University and by the other external lecturers. These all play such a vital part in maintaining the standard of the training. Another asset is the close proximity of the Witwatersrand School of Physiotherapy which makes it possible to build up strong co-operation in the field of examinations, and stimulates a happy rivalry so good for all of us.

The school is most fortunate in its geographical position, being situated in the grounds of the Orthopaedic Hospital and close to the other Pretoria Hospitals where the students have excellent opportunities of clinical experience.

We three, Miss Meredith, Miss Savin and I, took our first holiday at Christmas, and this is when we got some brief glimpses of Physiotherapy outside our own immediate domain. We had a wonderful trip by car to the Cape and back, we travelled there by the inland route and came back part of the way along the coast, we really had a "Bus-man's" holiday as we took every opportunity of visiting the hospitals and Physiotherapy Departments wherever possible.

We were very impressed with the new Physiotherapy School in Cape Town, Miss Roper's eighteen months of hard work and detailed planning had resulted in a most attractive building, the latest thing in modern decor, and equipped with the most up-to-date apparatus. It was rather a disappointment to us that the students were on holiday so we did not see the school in action.

We felt completely at home in the Physiotherapy Department of the Groote Schuur Hospital, it was so exactly like a busy Department at home, and the fact that it was staffed by members of the C.S.P., strengthened that feeling.
After Cape Town we visited Physiotherapy Departments in Port Elizabeth, East London, King Williamstown, Bloemfontein, Welkom and Kroonstad and in every one of these places two major facts impressed themselves on our notice, the quantity and very excellent quality of the work being done, and the very. great shortage of staff. We would like to thank all the Physiotherapists in these various departments, who made us so very welcome, who showed us round their departments and hospitals and who touched our hearts with their plea for assistance, in many instances the Physiotherapists were working alone in a department which had an establishment of three or four and were long overdue for leave, but their concern for their patients held them back from taking it.

We noticed that in Cape Town with its strong social and cultural attractions the staffing problem did not arise, as so many overseas Physiotherapists are attracted there, whereas in the smaller places with work equally vital and interesting the departments were almost without exception short staffed. I felt proud to meet so many Pretoria trained Physiotherapists, all were doing such excellent work and were absolutely on their toes, I certainly resolved that any recruitment on my part should be directed to solving the staff problems of these smaller towns.

Very shortly after I settled in Pretoria, I was invited to serve on the Executive Committee of the South African Association of Physiotherapy, and my attendance at the Committee Meetings where I have heard the problems of Physiotherapy in this country discussed, has given me a "bird's eye" view of conditions in South Africa. I am impressed by the vigour and vitality of an organisation so comparatively young in years but so strong in it's grip, and so comprehensive and thorough in it's work. I am sure the profession has started to climb up "the right ladder, it's acceptance by the South African Medical and Dental Council, the sound basis on which the Society works, it's farsighted policy of expansion, it's membership of the World Confederation of Physical Therapy and it's courage to plan for what seems the unattainable should give to every Physiotherapist in South Africa great confidence and professional pride.

If I were to return to England now, and were asked by a colleague what I thought of Physiotherapy in South Africa, I should say without hesitation that I considered that the facilities for training were excellent, that the scope and standard of work in most branches was equal to or higher than in many countries.

Because the country is new and the profession here comparatively young, the feeling of pioneering is most stimulating and gives to the work the slight impetus of excitement. There are enormous fields of work for the Physiotherapist as yet untapped, and far more could be done to demonstrate physiotherapy to the Medical Profession.

It will require great courage and self-sacrifice on the part of all Physiotherapists to overcome the problems created by the very vastness of the country, perhaps the greatest being professional loneliness, the outcome of the isolation of so many of its towns and the difficulties of maintaining professional contacts.

I should like to take this opportunity of thanking all the Physiotherapists who have made me so welcome in South Africa, particularly in Pretoria, it has been a wonderful and stimulating experience. 